\title{
Thoracic empyema in patients with liver cirrhosis: Clinical characteristics and outcome analysis of thoracoscopic management
}

\author{
Ke-Cheng Chen, MD, ${ }^{\text {a,c,d,e,f }}$ Jou-Wei Lin, MD, MPH, PhD, ${ }^{\mathrm{b}}$ Yu-Ting Tseng, MD, ${ }^{\mathrm{a}}$ Shuenn-Wen Kuo, MD, ${ }^{\mathrm{f}}$ \\ Pei-Ming Huang, MD, ${ }^{f}$ Hsao-Hsun Hsu, MD, PhD, ${ }^{f}$ Jang-Ming Lee, MD, PhD, ${ }^{f}$ and \\ Jin-Shing Chen, MD, $\mathrm{PhD}^{\mathrm{a}, \mathrm{f}}$
}

\begin{abstract}
Objective: Thoracic empyema in cirrhotic patients is a challenging situation, and the clinical characteristics are rarely reported. The objective of this study was to report the clinical characteristics among this group and to evaluate whether thoracoscopic intervention would affect clinical outcomes.
\end{abstract}

\begin{abstract}
Methods: Between 2001 and 2010, we retrospectively reviewed the clinical characteristics, bacteriologic studies, and treatment outcomes of 63 cirrhotic patients with thoracic empyema. A propensity-score based process, matched on age, sex, diabetes mellitus, malignancy, cause, and Child-Pugh classification (A, B, or C), was performed to equalize potential prognostic factors in thoracoscopy and nonthoracoscopy groups. The KaplanMeier curve and log-rank test were applied to compare the survival to discharge between the 2 matched groups.

Results: The median patient age was 61 years. Thirty-two patients (51\%) underwent thoracoscopic management, and the remaining patients underwent thoracocentesis or tube thoracostomy. The median hospital stay was 28 days, and 19 patients $(30 \%)$ had in-hospital mortality. Multivariate analysis showed that Child-Pugh $\mathrm{C}$ disease and positive blood cultures were risk factors for in-hospital mortality $(P=.016$ and .027 , respectively), whereas thoracoscopic management may be favorable for survival $(P=.041)$. The propensity scorematched analysis showed a significant reduction in intensive care unit stay $(P=.044)$ in the thoracoscopy group. Kaplan-Meier survival analysis revealed a higher survival to discharge, favoring thoracoscopy over nonthoracoscopy treatment $(P=.035)$.
\end{abstract}

Conclusions: Management of thoracic empyema in cirrhotic patients is complicated and associated with a high mortality. With proper patient selection, thoracoscopic management is feasible and may provide a better chance of survival. (J Thorac Cardiovasc Surg 2012;143:1144-51)

Thoracic empyema in patients with liver cirrhosis poses a significant challenge to the clinician. In addition to a higher risk of hepatic failure, the pleural infection makes cirrhotic patients more susceptible to critical condition and mortality. Cirrhosis is also regarded as a contraindication to major surgery because of frequent hemostatic abnormalities and malnutrition, which lead to increasing postoperative morbidity or mortality. ${ }^{1}$ Patients with cirrhosis are reported

From the Department of Surgery ${ }^{\mathrm{a}}$ and Cardiovascular Center and Health Management

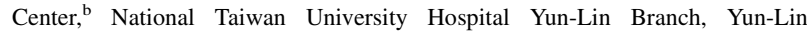
County, Taiwan; National Taiwan University Hospital Chu-Tung Branch, ${ }^{c}$ Hsin-Chu County, Taiwan; National Taiwan University Hospital Hsin-Chu Branch, ${ }^{\mathrm{d}}$ Hsin-Chu City, Taiwan; Institute of Biomedical Engineering, College of Medicine and College of Engineering, National Taiwan University, ${ }^{\mathrm{e}}$ Taipei, Taiwan; and Department of Surgery, ${ }^{\mathrm{f}}$ National Taiwan University Hospital and National Taiwan University College of Medicine, Taipei, Taiwan.

This study was supported by research grants from National Taiwan University Hospital Yun-Lin Branch, Yun-Lin County, Taiwan (NTUHYL 98-NO23; 99-NO20; 100-M002 and 99-G001).

Disclosures: Authors have nothing to disclose with regard to commercial support.

Received for publication Aug 12, 2011; revisions received Nov 9, 2011; accepted for publication Dec 14, 2011; available ahead of print Jan 13, 2012.

Address for reprints: Jin-Shing Chen, MD, PhD, Department of Surgery, National Taiwan University Hospital, No. 7, Chung Shan South Road, Taipei, Taiwan, 100 (E-mail: chenjs@ntu.edu.tw).

$0022-5223 / \$ 36.00$

Copyright (c) 2012 by The American Association for Thoracic Surgery doi:10.1016/j.jtcvs.2011.12.024 to die because of postoperative complications from hepatic failure with intractable ascites. ${ }^{1}$ Moreover, surgical procedures have a high risk of hemorrhage, infection, and metabolic imbalance, and are sometimes withheld from cirrhotic patients for fear of complications.

Since its introduction, video-assisted thoracoscopic surgery (VATS) has become an attractive modality for treating complicated empyema because of its minimal invasiveness and satisfactory efficacy. ${ }^{2-7}$ Although clinical evidence showing VATS is beneficial in the thoracic empyema, the clinical characteristics and the role of VATS in managing patients with empyema with liver cirrhosis are unknown. We report our 10-year experience in managing cirrhotic patients with empyema, especially focusing on analysis of the risk factors. We also examine the therapeutic effect of thoracoscopy in this specific group of patients, compared with nonthoracoscopic treatment, on survival to discharge.

\section{MATERIALS AND METHODS Patients}

The medical records of all patients with thoracic empyema who were discharged with a diagnosis of liver cirrhosis at the National Taiwan University Hospital and National Taiwan University Hospital Yun-Lin Branch, a 3200-bed tertiary medical center, from January 2001 to June 2010 were reviewed retrospectively. Exclusion criteria included empyema caused by 


\author{
Abbreviations and Acronyms \\ $\mathrm{CI}=$ confidence interval \\ $\mathrm{HBV}=$ hepatitis B virus \\ $\mathrm{HCV}=$ hepatitis $\mathrm{C}$ virus \\ ICU = intensive care unit \\ MRSA $=$ methicillin-resistant Staphylococcus \\ aureus \\ OR $=$ odds ratio \\ VATS $=$ video-assisted thoracoscopic surgery
}

esophageal rupture, mediastinitis, tuberculosis, fungal infection, and postoperative empyema. Information collected included demographic features, clinical characteristics, microbiologic and laboratory data, radiographic studies, hospital course, intervention modality, and treatment outcome.

The diagnosis of thoracic empyema was made if a patient had at least 1 of the following conditions: the presence of purulent material in the pleural space, positive result for loculated pleural fluid culture or Gram stain for microorganisms, and biochemical evidence suggestive of empyema. ${ }^{8} \mathrm{~A}$ diagnosis of liver cirrhosis was based on the patients' clinical histories and findings of typical morphologic change of the liver and spleen. The severity of liver cirrhosis was graded according to the Child-Pugh classification, which is based on the following 5 factors graded from 1 to 3: degree of encephalopathy, ascites, prothrombin time, level of albumin, and total bilirubin. ${ }^{9}$ The cause of liver cirrhosis was established according to standard criteria for infection with hepatitis B virus (HBV) (positive serum test for hepatitis $B$ surface antigen), hepatitis $\mathrm{C}$ virus (HCV) (seropositivity for $\mathrm{HCV}$ antibody), coinfection $\mathrm{HBV}$ and $\mathrm{HCV}$, or alcoholism related. Other causes included autoimmune disease and cardiac liver cirrhosis. When no cause was identified, liver cirrhosis was classified as cryptogenic.

The Research Ethics Committee of National Taiwan University Hospital approved this study and waived the requirement for informed consent because of its retrospective nature (approval number: 201102015RC).

\section{Demographic and Clinical Features}

The algorithm for patient selection is shown in Figure 1. Sixty-three of 888 patients had liver cirrhosis $(7.1 \%)$. The characteristics and demographics of the cirrhotic patients with thoracic empyema are listed in Table 1 . The median age was 61 years, and 39 patients were male. Most patients $(87.3 \%)$ had chronic underlying diseases or associated medical conditions, including malignancy (33.3\%), diabetes mellitus (31.7\%), hepatic hydrothorax (30.2\%), chronic renal insufficiency (22.2\%), and congestive heart failure $(11.1 \%)$. Among those with malignancy, 18 patients $(85.7 \%)$ had hepatocellular carcinoma, 2 patients had buccal cancer, and 1 patient had nasopharyngeal cancer. The causes of cirrhosis, the number of Child-Pugh A, B, and C cases, and the inciting infections of thoracic empyema are listed in Table 1.

\section{Management}

All patients received empiric broad-spectrum intravenous antibiotics as soon as the diagnosis of thoracic empyema was suspected. Once the causative pathogen was cultured, the antibiotics were adjusted according to sensitivity testing results. Sonography-guided thoracocentesis was performed on all patients, and the aspirates were sent for laboratory examination. Chest computed tomography was performed to evaluate the extent of the empyema and the severity of pulmonary parenchymal lesions, and all patients were noted with fibropurulent stage in this study. The primary physician selected repeated thoracocentesis, pigtail insertion, or tube thoracostomy as the method of drainage. If drainage was not effective, chest surgeons were consulted to evaluate the feasibility of thoracoscopic management. Before diagnosis, thoracocentesis, and drainage of the empyema, patients may have required albumin and blood component infusions to improve hypoalbuminemia, anemia, thrombocytopenia, or prolonged bleeding time or coagulation time. Patients were admitted to the intensive care unit (ICU) for respiratory distress, organ failure, or unstable vital signs requiring the use of inotropic agents, whether with or without surgical intervention.

\section{Thoracoscopic Procedures}

The patients who were treated with thoracoscopy underwent general anesthesia using double-lumen endotracheal tubes for selective 1-lung ventilation. The procedure was performed by means of a 3-port access. On the basis of preoperative sonography and computed tomography, suitable intercostal sites were selected for port placement. Fluid, loculations, and septa were removed under endoscopic vision. Adherent peel was carefully removed from visceral pleural surface, and the lung was freed circumferentially from the apex to the diaphragm. Complete decortication of the visceral pleura and the fissures was performed by use of an endoscopic dissector device and a peanut dissector as in open decortication. At the end of the procedure, 2 chest tubes were placed. The abscess and necrotic tissue from the empyema collection were sent for bacterial cultures and pathologic examination. The postoperative duration of drainage depended on the patient's clinical progress and results of the cultures of fluids aspirated from the drainage tubes.

\section{Statistical Analyses}

The primary outcome variable assessed in this study was in-hospital mortality. Categoric variables were compared using chi-square and Fisher exact tests, and continuous variables were compare with the Student $t$ test. The median of hospital stays was compared by Mann-Whitney $U$ test. Univariate analyses were performed to assess the association between each risk factor and in-hospital mortality. Variables that had a $P$ value less than .1 in the univariate analyses were subjected to multivariate analysis using a stepwise binary logistic regression model. Odds ratios (ORs) and $95 \%$ confidence intervals (CIs) were calculated to determine significance by multivariate analysis. $P$ values of less than .05 were regarded as significant. Statistical analyses were performed using SPSS release 18 (SPSS Inc, Chicago, Ill), and all statistical tests were 2 -sided.

\section{Propensity Score-Matching Methods}

Propensity score matching is a method used to balance observed covariates in the 2 treatment groups. In this study, the propensity score was the conditional probability for receiving thoracoscopy, as a binary dependent variable, under a set of measurements. Age, sex, diabetes mellitus, malignancy, cause of empyema, and Child-Pugh class of liver cirrhosis were added into a nonparsimonious multivariable logistic regression model to predict the effect of thoracoscopy. The predicted probability derived from the logistic equation was used as the propensity score for each individual. Sixty-three patients were pooled and sorted according to their propensity score in ascending order. The selection process began from the first 2 cases with the lowest propensity score. If 1 case underwent thoracoscopy and the other case underwent nonthoracoscopy management, both were selected as a matched pair. If this was not the case, then 4 cases were included. In the same way, thoracoscopy and nonthoracoscopy cases were matched by their propensity score in 1:1, 2:2, 3:3, or 4:4 blocks. A patient who did not have a suitable match within the acceptable rank range was excluded from further analysis, and the matching process moved down the sort list until all possible matched pairs were included. ${ }^{10}$ The selected patients formed well-matched 1:1 pairs in both groups (thoracoscopy and nonthoracoscopy). Kaplan-Meier curves, with follow-up until hospital discharge, were plotted to show survival trend. Log-rank test was used to compare the difference between the 2 matched groups. The survival time 


\section{1,198 patients with diagnosis of empyema}
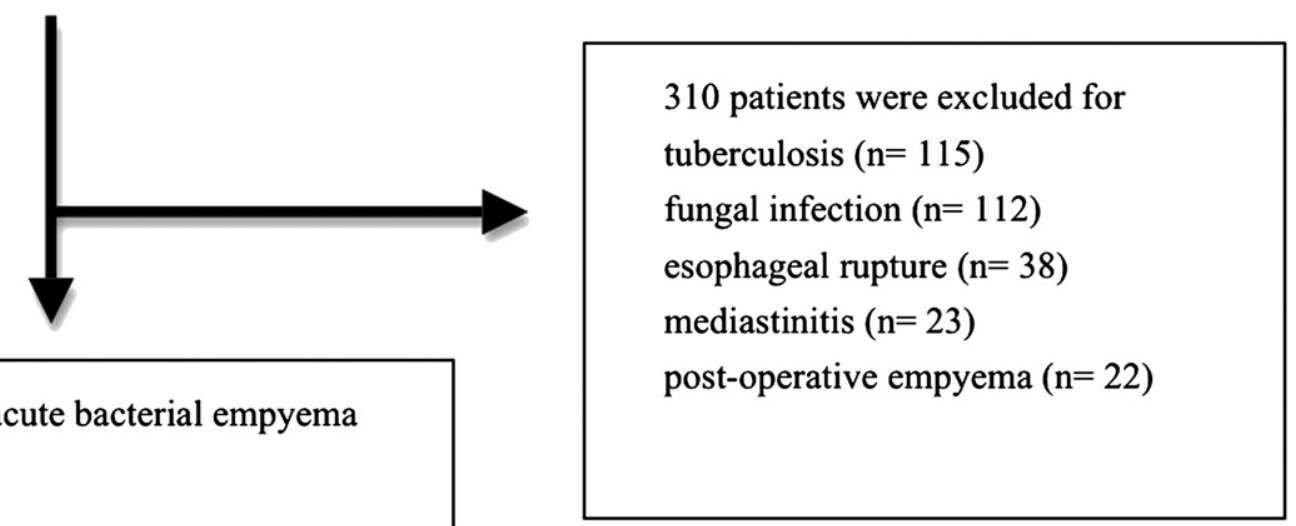

888 patients with acute bacterial empyema enrolled

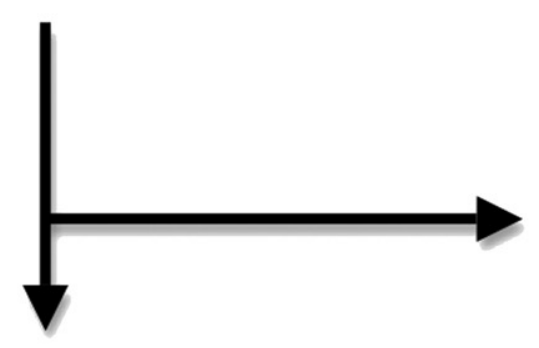

825 empyema patients without liver cirrhosis

63 empyema patients with liver cirrhosis enrolled

FIGURE 1. Algorithm for patient selection.

was defined as the duration from admission to death in the mortality cases and as the duration from admission to discharge in the survivors. A logistic regression model was used for the propensity score calculation using SPSS release 18 (SPSS Inc). Propensity scores in both the thoracoscopy and nonthoracoscopy groups were used to draw box-plots.

\section{RESULTS}

\section{Bacteriology}

Bacteriologic results from samples obtained from the empyema specimens or blood showed 41 patients $(65 \%)$ with positive culture results, including positive empyema cultures in 38 patients and positive blood cultures in 12 patients (Table 1). A total of 48 microorganisms were identified, including polymicrobial infections in 4 patients $(9.8 \%)$ and monopathogens in 37 patients $(90.2 \%)$. The most common pathogen was Klebsiella pneumonia, found in 11 patients, which was followed by methicillinresistant Staphylococcus aureus (MRSA) in 7 patients (Table 2). When the cause of empyema was stratified by the pathogen isolated, we found $K$ pneumoniae was the most common pathogen in patients with parapneumonic empyema, and Escherichia coli and MRSA were more common in empyema due to hepatic hydrothorax (Table 2).

\section{Treatment and Outcome}

Of the 63 patients, 32 finally underwent thoracoscopic debridement and drainage of the empyema. The median duration from admission to thoracoscopy was 3 days (range, 1-10 days). The median operation time was 113 minutes (range, 48-172 minutes), and the median intraoperative blood loss was $325 \mathrm{~mL}$ (range, $30-580 \mathrm{~mL}$ ). After the operation, 4 patients $(12.5 \%)$ required additional procedures for complications, including 1 patient who required repeated thoracoscopy for hemothorax and 3 patients who required open drainage for residual empyema. The remaining $31 \mathrm{pa}-$ tients underwent thoracentesis or tube thoracostomy. The median hospital stay was 28 days. Forty-eight patients $(76.2 \%)$ were admitted to the ICU for critical conditions, with a ICU stay of 10 days. After treatment, 44 patients survived to discharge, whereas the remaining 19 patients $(30.2 \%)$ died in the hospital (Table 1$)$. The mortality rates 
TABLE 1. Clinical characteristics and treatment outcome of 63 cirrhotic patients with empyema

\begin{tabular}{|c|c|}
\hline Variables & $\begin{array}{c}\text { Result } \\
\text { No. }(\%) \text {, or median (range) }\end{array}$ \\
\hline Age, y & $61(38 \sim 80)$ \\
\hline Male & $39(61.9 \%)$ \\
\hline Ever smoker & $33(52.4 \%)$ \\
\hline Right sided & $43(68.3 \%)$ \\
\hline Comorbidity & $55(87.3 \%)$ \\
\hline Malignancy & $21(33.3 \%)$ \\
\hline Diabetes mellitus & $20(31.7 \%)$ \\
\hline Hepatic hydrothorax & $19(30.2 \%)$ \\
\hline Chronic renal insufficiency & $16(25.4 \%)$ \\
\hline Congestive heart failure & $7(11.1 \%)$ \\
\hline \multicolumn{2}{|l|}{ Cause of liver cirrhosis } \\
\hline HBV & $28(44.4 \%)$ \\
\hline $\mathrm{HCV}$ & $14(22.2 \%)$ \\
\hline $\mathrm{HBV}$ and $\mathrm{HCV}$ & $5(7.9 \%)$ \\
\hline Alcoholism & $7(11.1 \%)$ \\
\hline Autoimmune diseases & $5(7.9 \%)$ \\
\hline Others & $4(6.3 \%)$ \\
\hline \multicolumn{2}{|l|}{ Child-Pugh class } \\
\hline A & $21(33.3 \%)$ \\
\hline $\mathrm{B}$ & $17(27.0 \%)$ \\
\hline $\mathrm{C}$ & $25(39.7 \%)$ \\
\hline \multicolumn{2}{|l|}{ Cause of empyema } \\
\hline Pneumonia & $37(58.7 \%)$ \\
\hline Hepatic hydrothorax & $19(30.2 \%)$ \\
\hline Others & $7(11.1 \%)$ \\
\hline Positive bacterial culture & $41(65.1 \%)$ \\
\hline Empyema & $38(60.3 \%)$ \\
\hline Blood & $12(19.0 \%)$ \\
\hline Thoracoscopic management & $32(50.8 \%)$ \\
\hline Total hospital stay, d & $28(5 \sim 150)$ \\
\hline ICU stay, d & $10(0 \sim 89)$ \\
\hline Mortality & $19(30.2 \%)$ \\
\hline
\end{tabular}

$H B V$, Hepatitis B virus; $H C V$, hepatitis $\mathrm{C}$ virus; $I C U$, intensive care unit.

stratified by Child-Pugh cirrhosis class were $14.3 \%(3 / 21)$ in class A, $5.9 \%(1 / 17)$ in class B, and 60\% (15/25) in class C. The causes of mortality included sepsis in 9 patients, multiple organ failure in 5 patients, hepatic failure in 4 patients, and intractable gastrointestinal bleeding in 1 patient.

To identify the factors associated with in-hospital mortality, the clinical characteristics, bacteriology, and management between survivors and nonsurvivors are summarized and compared in Table 3 by univariate analysis. We found that patients with Child-Pugh class $\mathrm{C}$ and positive blood cultures were associated with a higher rate of in-hospital mortality. On the other hand, patients with male gender, with Child-Pugh class B, and undergoing thoracoscopic management were associated with a lower rate of inhospital mortality. Multivariate logistic regression analysis showed that Child-Pugh class C (OR, 6.89; 95\% CI, 1.4333.18 ) and positive blood cultures (OR, 13.97; 95\% CI,
TABLE 2. Microorganisms $(n=48)$ isolated from 41 patients

\begin{tabular}{|c|c|c|c|c|}
\hline \multirow[b]{2}{*}{ Isolates } & \multirow[b]{2}{*}{$\begin{array}{c}\text { All } \\
\text { isolates } \\
\mathrm{n}=\mathbf{4 8}\end{array}$} & \multicolumn{3}{|c|}{ Cause of empyema } \\
\hline & & $\begin{array}{c}\text { Pneumonia } \\
\mathbf{n}=\mathbf{2 7}\end{array}$ & $\begin{array}{c}\text { Hepatic } \\
\text { hydrothorax } \\
\mathbf{n}=13 \\
\end{array}$ & $\begin{array}{c}\text { Others } \\
\mathbf{n}=\mathbf{8}\end{array}$ \\
\hline $\begin{array}{l}\text { Klebsiella } \\
\text { pneumoniae }\end{array}$ & $11(22.9 \%)$ & $8(29.6 \%)$ & $1(7.7 \%)$ & $2(25.0 \%$ \\
\hline$M R S A$ & $7(14.6 \%)$ & $3(11.1 \%)$ & $2(15.4 \%)$ & $2(25.0 \%$ \\
\hline Escherichia coli & $5(10.4 \%)$ & $2(7.4 \%)$ & $2(15.4 \%)$ & $1(12.5 \%$ \\
\hline $\begin{array}{l}\text { Streptococcus } \\
\text { constellatus }\end{array}$ & $3(6.3 \%)$ & $2(7.4 \%)$ & $1(7.7 \%)$ & 0 \\
\hline $\begin{array}{c}\text { Enterobacter } \\
\text { cloacae }\end{array}$ & $3(6.3 \%)$ & 0 & $1(7.7 \%)$ & $2(25.0 \%$ \\
\hline$M S S A$ & $2(4.2 \%)$ & $1(3.7 \%)$ & $1(7.7 \%)$ & 0 \\
\hline Enterococcus & $2(4.2 \%)$ & $1(3.7 \%)$ & 0 & $1(12.5 \%$ \\
\hline $\begin{array}{r}\text { Pseudomonas } \\
\text { aeruginosa }\end{array}$ & $2(4.2 \%)$ & $2(7.4 \%)$ & 0 & 0 \\
\hline $\begin{array}{l}\text { Aeromonas } \\
\text { hydrophila }\end{array}$ & $2(4.2 \%)$ & $1(3.7 \%)$ & $1(7.7 \%)$ & 0 \\
\hline A sobria & $2(4.2 \%)$ & $1(3.7 \%)$ & $1(7.7 \%)$ & 0 \\
\hline$S$ intermedius & $2(4.2 \%)$ & $1(3.7 \%)$ & $1(7.7 \%)$ & 0 \\
\hline$S$ anginosus & $2(4.2 \%)$ & $2(7.4 \%)$ & 0 & 0 \\
\hline MRCNS & $2(4.2 \%)$ & $1(3.7 \%)$ & $1(7.7 \%)$ & 0 \\
\hline$P D R A B$ & $2(4.2 \%)$ & $1(3.7 \%)$ & $1(7.7 \%)$ & 0 \\
\hline Salmonella & $1(2.1 \%)$ & $1(3.7 \%)$ & 0 & 0 \\
\hline
\end{tabular}

MRSA, Methicillin-resistant Staphylococcus aureus; MSSA, methicillin-sensitive Staphylococcus aureus; MRCNS, methicillin-resistant coagulase-negative staphylococci; PDRAB, pan-resistant Acinetobacter baumaanii.

1.36-143.57) were risk factors for in-hospital mortality, whereas thoracoscopic management may be favorable to survival (OR, 0.16; 95\% CI, 0.03-0.93) (Table 4).

\section{Thoracoscopic Versus Nonthoracoscopic Management}

To analyze the role of thoracoscopic management in cirrhotic patients with empyema, patients were grouped according to receiving or not receiving thoracoscopic management. There were 32 patients in the thoracoscopy group and 31 patients in the nonthoracoscopy group. $\mathrm{Pa}-$ tients in the thoracoscopy group were associated with a lower rate of Child-Pugh class C $(21.9 \%$ vs $58.1 \%$, $P=.005$ ), a shorter duration of ICU stay (median, 6 vs 15.0 days; $P<.001$ ), and a lower rate of in-hospital mortality $(12.5 \%$ vs $48.4 \%, P=.003)$. The total hospital stay between the 2 groups was comparable (Table 5). The propensity score-matching method selected 19 patients from the thoracoscopy group and 19 patients from the nonthoracoscopy group for further analysis (Figure 2, A and $B$ ). Baseline characteristics, including age, gender, comorbidity, and Child-Pugh class, were all comparable in the 2 groups. The results showed that only ICU stay was longer in the nonthoracoscopy group (median, 13 days) than in the thoracoscopy group (6 days, $P=.044)$. The difference of in-hospital mortality was nonsignificant $(P=.714$, Table 6). Kaplan-Meier survival analysis revealed a higher 
TABLE 3. Clinical characteristics, bacteriology, and management between survivors and nonsurvivors

\begin{tabular}{|c|c|c|c|}
\hline \multirow[b]{2}{*}{ Variables } & $\begin{array}{c}\text { Survivors } \\
(N=44)\end{array}$ & $\begin{array}{c}\text { Nonsurvivors } \\
(\mathbf{N}=19) \\
\end{array}$ & \multirow[b]{2}{*}{$\begin{array}{c}P \\
\text { value }\end{array}$} \\
\hline & $\begin{array}{c}\text { No. }(\%), \text { or } \\
\text { median (range) }\end{array}$ & $\begin{array}{c}\text { No. }(\%), \text { or } \\
\text { median (range) }\end{array}$ & \\
\hline Age, y & $61(38 \sim 80)$ & $63(49 \sim 77)$ & .250 \\
\hline Male & $31(70.5 \%)$ & $8(42.1 \%)$ & .048 \\
\hline Ever smoker & $25(56.8 \%)$ & $8(42.1 \%)$ & .410 \\
\hline Right sided & $29(65.9 \%)$ & $14(73.7 \%)$ & .769 \\
\hline \multicolumn{4}{|l|}{ Comorbidity } \\
\hline Malignancy & $13(29.5 \%)$ & $8(42.1 \%)$ & .381 \\
\hline Diabetes mellitus & $15(34.1 \%)$ & $5(26.3 \%)$ & .770 \\
\hline Hepatic hydrothorax & $12(27.3 \%)$ & $7(36.8 \%)$ & .552 \\
\hline Chronic renal insufficiency & $8(18.2 \%)$ & $8(42.1 \%)$ & .061 \\
\hline Congestive heart failure & $5(11.4 \%)$ & $2(10.5 \%)$ & 1.000 \\
\hline \multicolumn{3}{|l|}{ Child-Pugh class } & $<.001$ \\
\hline A & $18(40.9 \%)$ & $3(15.8 \%)$ & .080 \\
\hline B & $16(36.4 \%)$ & $1(5.3 \%)$ & .013 \\
\hline $\mathrm{C}$ & $10(22.7 \%)$ & $15(78.9 \%)$ & $<.001$ \\
\hline \multicolumn{4}{|l|}{ Cause of empyema } \\
\hline Pneumonia & $26(59.1 \%)$ & $11(57.9 \%)$ & 1.000 \\
\hline Hepatic hydrothorax & $12(27.3 \%)$ & $7(36.8 \%)$ & .552 \\
\hline Others & $6(13.6 \%)$ & $1(5.3 \%)$ & .664 \\
\hline \multicolumn{4}{|l|}{ Positive culture } \\
\hline Empyema & $26(59.1 \%)$ & $12(63.2 \%)$ & 1.000 \\
\hline Blood & $3(6.8 \%)$ & $9(47.4 \%)$ & $<.001$ \\
\hline \multicolumn{4}{|l|}{ Causing pathogen } \\
\hline Klebsiella pneumoniae & $7(15.9 \%)$ & $4(21.1 \%)$ & 1.000 \\
\hline MRSA & $4(9.1 \%)$ & $3(15.8 \%)$ & .160 \\
\hline Escherichia coli & $2(4.5 \%)$ & $3(15.8 \%)$ & .160 \\
\hline Others & $18(40.9 \%)$ & $7(36.8 \%)$ & 1.000 \\
\hline Thoracoscopic management & $28(63.6 \%)$ & $4(21.1 \%)$ & .003 \\
\hline
\end{tabular}

MRSA, Methicillin-resistant Staphylococcus aureus.

survival to discharge, favoring thoracoscopy over nonthoracoscopy treatment (log-rank $P=.035$, Figure 3$)$.

\section{DISCUSSION}

Our study aimed to identify the clinical characteristics and prognostic factors affecting in-hospital mortality and to analyze the role of thoracoscopic management in cirrhotic patients with thoracic empyema. The study showed that management of thoracic empyema in cirrhotic patients was challenging and associated with a high mortality rate, especially when patients had Child-Pugh $\mathrm{C}$ disease and

TABLE 4. Multivariant logistic regression analysis of risk factors affecting mortality

\begin{tabular}{lrlc}
\hline \multicolumn{1}{c}{ Associated variables } & OR & \multicolumn{1}{c}{$\mathbf{9 5} \%$ CI } & $\boldsymbol{P}$ value \\
\hline Male & 0.51 & $0.10 \sim 2.59$ & .419 \\
Chronic renal insufficiency & 1.21 & $0.17 \sim 8.50$ & .848 \\
Child-Pugh C* & 6.89 & $1.43 \sim 33.18$ & .016 \\
Positive blood culture & 13.97 & $1.36 \sim 143.57$ & .027 \\
Thoracoscopic management & 0.16 & $0.03 \sim 0.93$ & .041 \\
\hline
\end{tabular}

*Child-Pugh C vs Child-Pugh A and B.
TABLE 5. Clinical characteristics, bacteriology, and treatment outcome between patients undergoing thoracoscopic and nonthoracoscopic management

\begin{tabular}{|c|c|c|c|}
\hline \multirow[b]{2}{*}{ Variables } & $\begin{array}{l}\text { Thoracoscopy } \\
(\mathbf{N}=32)\end{array}$ & $\begin{array}{l}\text { Nonthoracoscopy } \\
\qquad(\mathbf{N}=\mathbf{3 1})\end{array}$ & \multirow[b]{2}{*}{$\begin{array}{c}P \\
\text { value }\end{array}$} \\
\hline & $\begin{array}{c}\text { No. }(\%), \text { or } \\
\text { median (range) }\end{array}$ & $\begin{array}{c}\text { No. }(\%), \text { or } \\
\text { median (range) }\end{array}$ & \\
\hline Age, y & $59(38-80)$ & $62(38-77)$ & .390 \\
\hline Male & $22(68.8 \%)$ & $17(54.8 \%)$ & .310 \\
\hline Ever smoker & $18(56.3 \%)$ & $15(48.4 \%)$ & .617 \\
\hline Right sided & $20(62.5 \%)$ & $23(74.2 \%)$ & .419 \\
\hline \multicolumn{4}{|l|}{ Comorbidity } \\
\hline Malignancy & $11(34.4 \%)$ & $10(32.3 \%)$ & 1.000 \\
\hline Diabetes mellitus & $14(43.8 \%)$ & $6(19.4 \%)$ & .060 \\
\hline Hepatic hydrothorax & $6(18.8 \%)$ & $13(41.9 \%)$ & .060 \\
\hline $\begin{array}{l}\text { Chronic renal } \\
\text { insufficiency }\end{array}$ & $8(25.0 \%)$ & $8(25.8 \%)$ & 1.000 \\
\hline Congestive heart failure & $5(15.6 \%)$ & $2(6.5 \%)$ & .430 \\
\hline Child-Pugh class & & & .010 \\
\hline A & $13(40.6 \%)$ & $8(25.8 \%)$ & .290 \\
\hline B & $12(37.5 \%)$ & $5(16.1 \%)$ & .090 \\
\hline $\mathrm{C}$ & $7(21.9 \%)$ & $18(58.1 \%)$ & .005 \\
\hline \multicolumn{4}{|l|}{ Cause of empyema } \\
\hline Pneumonia & $21(65.6 \%)$ & $16(51.6 \%)$ & .311 \\
\hline Hepatic hydrothorax & $6(18.8 \%)$ & $13(41.9 \%)$ & .058 \\
\hline Others & $5(15.6 \%)$ & $2(6.45 \%)$ & .426 \\
\hline \multicolumn{4}{|l|}{ Positive culture } \\
\hline Empyema & $21(65.6 \%)$ & $17(54.8 \%)$ & 446 \\
\hline Blood & $5(15.6 \%)$ & $7(22.6 \%)$ & .536 \\
\hline \multicolumn{4}{|l|}{ Causing pathogen } \\
\hline Klebsiella pneumoniae & $6(18.8 \%)$ & $5(16.1 \%)$ & 1.000 \\
\hline MRSA & $5(15.6 \%)$ & $2(6.5 \%)$ & .430 \\
\hline Escherichia coli & $1(3.1 \%)$ & $4(12.9 \%)$ & .196 \\
\hline Others & $12(37.5 \%)$ & $13(41.9 \%)$ & .799 \\
\hline Total hospital stay, d & $29(9-150)$ & $28(5-56)$ & .140 \\
\hline ICU stay, d & $6(0-70)$ & $15(0-89)$ & $<.001$ \\
\hline Mortality & $4(12.5 \%)$ & $15(48.4 \%)$ & .003 \\
\hline
\end{tabular}

MRSA, Methicillin-resistant Staphylococcus aureus; ICU, intensive care unit.

positive blood cultures. Nonetheless, with comparable baseline patient characteristics, thoracoscopic management is feasible and may provide a better chance of survival than nonthoracoscopic management.

Taiwan is an $\mathrm{HBV}$ and $\mathrm{HCV}$ endemic area ${ }^{11}$; therefore, it was not surprising that the most common cause of liver cirrhosis was HBV infection, followed by HCV infection. ${ }^{12-14}$ In addition to liver cirrhosis, we also noticed that $87.3 \%$ of our patients with empyema had additional chronic underlying diseases or associated medical conditions. Comorbidities make the management of thoracic empyema more complicated and difficult. As a result, the median hospital stay was significantly longer (28 days) and overall in-hospital mortality was high $(30.2 \%)$.

The Child-Pugh class is a useful model to predict the relative risk of mortality in patients with end-stage liver disease, with or without surgical intervention. ${ }^{9,15,16}$ In the 

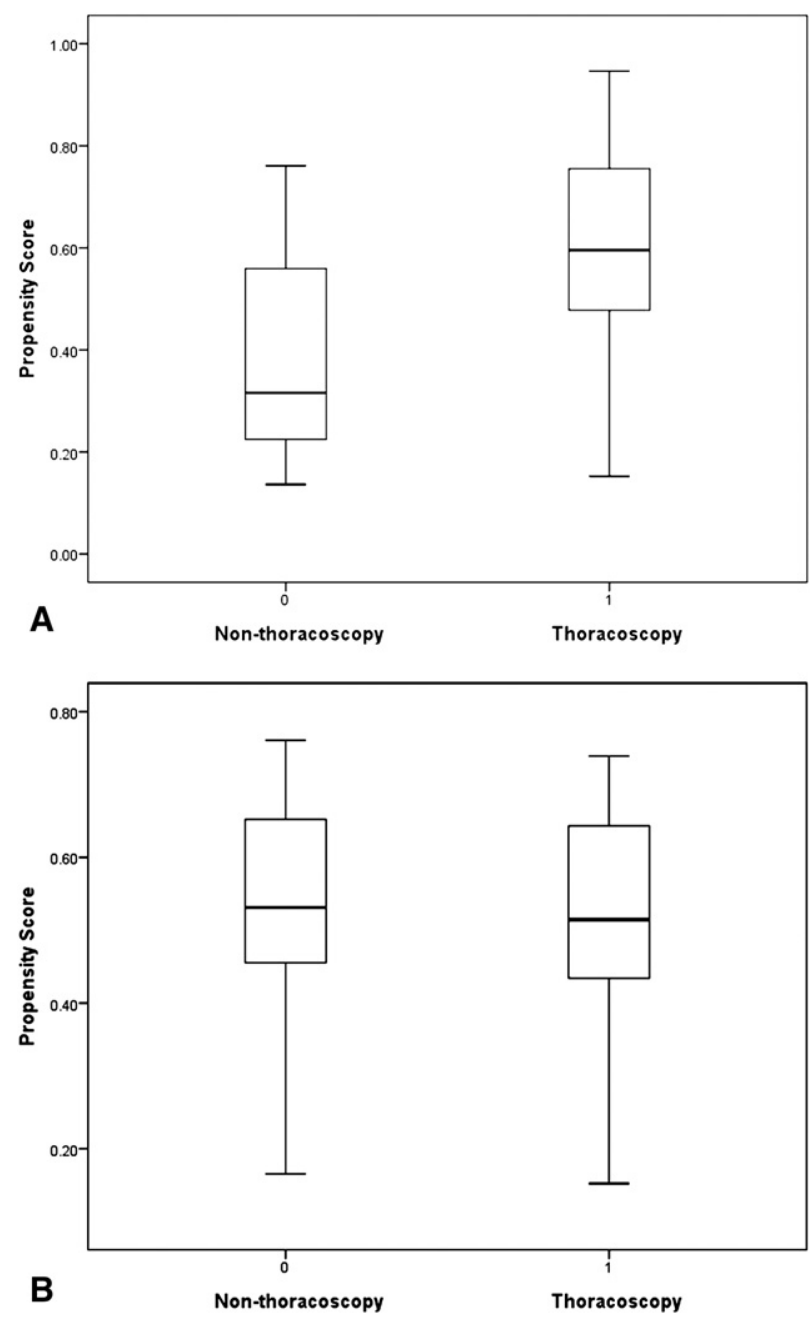

FIGURE 2. Propensity analysis. Distribution of propensity scores in the nonthoracoscopy and thoracoscopy groups before $(\mathrm{A}, \mathrm{n}=63)$ and after $(\mathrm{B}, \mathrm{n}=38)$ matching.

present study, Child-Pugh class $\mathrm{C}$ remained an important factor associated with a higher rate of in-hospital mortality in multivariate analysis. When the mortality rate was stratified by Child-Pugh class, mortality was $14.3 \%, 5.9 \%$, and $60 \%$ in Child-Pugh A, B, and C cases, respectively. In our patients, sepsis and hepatic failure were common causes of death. A possible explanation is that the immunity and hepatic reserve of patients with Child-Pugh class $\mathrm{C}$ cirrhosis were severely compromised, so that retained pus immediately resulted in sepsis and hepatic failure. ${ }^{1}$

As for coexisting cancer, 18 of 21 patients $(85.7 \%)$ had hepatocellular carcinoma. Although no significance was found, the cirrhotic patients with malignancy were worth noticing because their immunity may be weakened by the cancer.

Multivariate analysis also showed that positive blood cultures were an independent risk factor for a higher rate of mortality. Bacterial overgrowth, despite antibiotic therapy and
TABLE 6. Propensity analysis baseline characteristics and clinical outcomes between patients undergoing thoracoscopic and nonthoracoscopic management

\begin{tabular}{|c|c|c|c|}
\hline \multirow[b]{2}{*}{ Variables } & $\begin{array}{c}\text { Thoracoscopy } \\
(\mathbf{N}=19)\end{array}$ & $\begin{array}{l}\text { Nonthoracoscopy } \\
\qquad(\mathbf{N}=19)\end{array}$ & \multirow[b]{2}{*}{$\begin{array}{c}P \\
\text { value }\end{array}$} \\
\hline & $\begin{array}{c}\text { No. }(\%), \text { or } \\
\text { median (range) }\end{array}$ & $\begin{array}{c}\text { No. }(\%), \text { or } \\
\text { median (range) }\end{array}$ & \\
\hline Age, y & $57.5(38-80)$ & $60.5(38-77)$ & .676 \\
\hline Male & $14(73.7 \%)$ & $13(68.4 \%)$ & 1.000 \\
\hline Ever smoker & $12(63.2 \%)$ & $11(57.9 \%)$ & 1.000 \\
\hline Right sided & $12(63.2 \%)$ & $12(63.2 \%)$ & 1.000 \\
\hline \multicolumn{4}{|l|}{ Comorbidity } \\
\hline Malignancy & $7(36.8 \%)$ & $6(31.6 \%)$ & 1.000 \\
\hline Diabetes mellitus & $4(21.1 \%)$ & $5(26.3 \%)$ & 1.000 \\
\hline Hepatic hydrothorax & $6(31.6 \%)$ & $7(36.8 \%)$ & 1.000 \\
\hline $\begin{array}{l}\text { Chronic renal } \\
\text { insufficiency }\end{array}$ & $4(21.1 \%)$ & $3(15.8 \%)$ & 1.000 \\
\hline Congestive heart failure & $3(15.8 \%)$ & $1(5.3 \%)$ & .604 \\
\hline \multicolumn{4}{|l|}{ Child-Pugh class } \\
\hline A & $9(47.4 \%)$ & $8(42.1 \%)$ & 1.000 \\
\hline B & $4(21.1 \%)$ & $5(26.3 \%)$ & 1.000 \\
\hline $\mathrm{C}$ & $6(31.6 \%)$ & $6(31.6 \%)$ & 1.000 \\
\hline \multicolumn{4}{|l|}{ Cause of empyema } \\
\hline Pneumonia & $10(52.6 \%)$ & $10(52.6 \%)$ & 1.000 \\
\hline Hepatic hydrothorax & $6(31.6 \%)$ & $7(36.8 \%)$ & 1.000 \\
\hline Others & $3(15.8 \%)$ & $2(10.5 \%)$ & 1.000 \\
\hline \multicolumn{4}{|l|}{ Positive culture } \\
\hline Empyema & $12(63.2 \%)$ & $10(52.6 \%)$ & .743 \\
\hline Blood & $3(15.8 \%)$ & $4(21.1 \%)$ & 1.000 \\
\hline \multicolumn{4}{|l|}{ Causing pathogen } \\
\hline Klebsiella pneumoniae & $4(21.1 \%)$ & $2(10.5 \%)$ & .659 \\
\hline MRSA & $5(26.3 \%)$ & $1(5.3 \%)$ & .180 \\
\hline Escherichia coli & $1(5.3 \%)$ & $1(5.3 \%)$ & 1.000 \\
\hline Others & $8(42.1 \%)$ & $9(47.4 \%)$ & 1.000 \\
\hline Total hospital stay, d & $30(13-150)$ & $28(5-52)$ & .139 \\
\hline ICU stay, d & $6(0-70)$ & $13(0-89)$ & .044 \\
\hline Mortality & $4(21.1 \%)$ & $6(31.6 \%)$ & .714 \\
\hline
\end{tabular}

MRSA, Methicillin-resistant Staphylococcus aureus; ICU, intensive care unit.

drainage, indicates potentially greater bacterial toxicity or poor host immunity, resulting in poor outcomes. The results of our study showed that $K$ pneumoniae was the most common pathogen $(26.8 \%)$, as in many other patients with noncirrhotic empyema in Taiwan. ${ }^{17,18}$ When taking the cause of empyema into consideration, $K$ pneumonia was the main causative pathogen in parapneumonic empyema, whereas $E$ coli and MRSA were more common in hepatic hydrothorax. Our results are comparable to those of a previous report showing that $E$ coli was the most common pathogen in cirrhotic patients with spontaneous bacterial empyema. ${ }^{19}$

One of the most challenging decisions in treating cirrhotic patients with empyema is to select the optimal intervention to evacuate the pus and obliterate the pleural space. Open thoracotomy offers the best efficacy but is considered contraindicated in this patient group because of the high risk of perioperative complications. However, the role of 


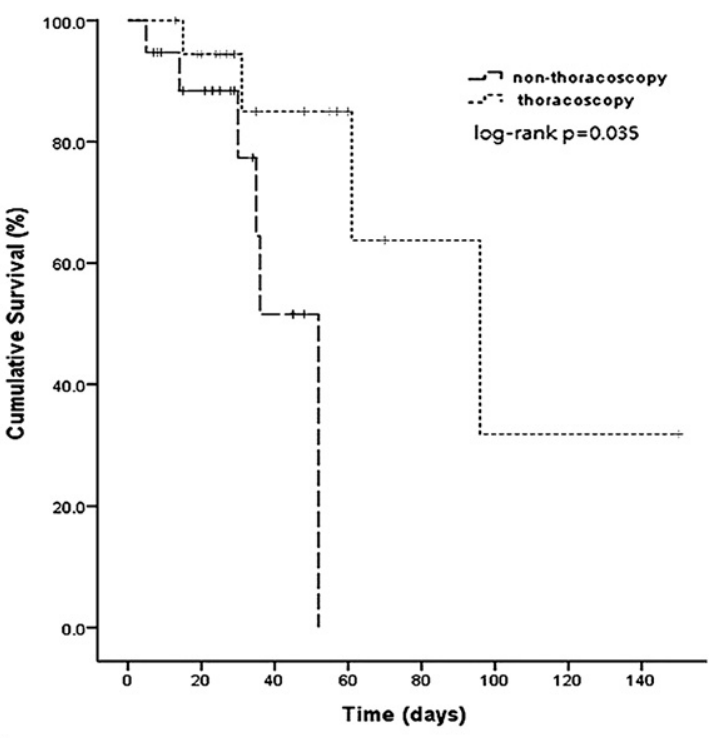

No. at Risk

$\begin{array}{lllllllll}\text { Non-thoracoscopy } & 19 & 13 & 4 & 0 & 0 & 0 & 0 & 0\end{array}$

FIGURE 3. Kaplan-Meier plot of the survival-to-discharge in the nonthoracoscopy and thoracoscopy groups.

thoracoscopy in managing these vulnerable patients has never been published. We found that thoracoscopic management was associated with a better chance of survival. Thoracoscopy provides minimal invasive access to the pleural space and is effective in evacuating viscous pleural fluid, lysing adhesions to promote the drainage of locules, and placing chest tubes in dependent regions of empyema under direct visualization. ${ }^{20,21}$ According to our experience, thoracoscopy drains most of the loculated empyema with minimal trauma to the pleural cavity, which is especially beneficial in cirrhotic patients with bleeding tendencies. In addition, less invasiveness and less surgical trauma of thoracoscopy also reduce impairment of patient immunity and inflammatory and cytokine responses. ${ }^{21-24}$ Although a repeated operation is sometimes required $(12.5 \%)$ for bleeding and inadequate drainage, thoracoscopy is feasible in selected patients after proper preoperative management.

\section{Limitations}

There are limitations to this study because it is retrospective. Selection bias may exist. It could be argued that the surgeons tended to choose patients with better general conditions because patients in the thoracoscopic group had a lower rate of Child-Pugh class $\mathrm{C}$ cirrhosis. Although the multivariate analysis showed that thoracoscopic management was an independent factor associated with better survival, some residual bias could still remain. We then performed the propensity score-matching method to avoid the bias. Because of the small case number after meticulous selection, there was no sufficient power to detect the difference in mortality rate at discharge (thoracoscopy $21.1 \%$ vs no thoracoscopy $31.5 \%, P=.714)$. However, there is still a statistically significant reduced hazard favoring thoracoscopy (log-rank test $P=.035$ ), indicating a prolonged median survival after the intervention. In addition, treatment policy was not standardized among physicians and surgeons, especially for the timing for thoracoscopic intervention. We believe that a prospective study with precise definitions of variables and standardized treatment protocols would be helpful in validating our results.

\section{CONCLUSIONS}

Thoracic empyema in cirrhotic patients represents a clinical challenge, with a high in-hospital mortality rate. Prompt identification of the causative pathogens and aggressive evacuation of pus from the pleural space are mandatory to rescue these vulnerable patients. Our results also showed that, with proper patient selection, thoracoscopic management is feasible and may provide a better chance of survival.

\section{References}

1. del Olmo JA, Flor-Lorente B, Flor-Civera B, et al. Risk factors for nonhepatic surgery in patients with cirrhosis. World J Surg. 2003;27:647-52.

2. Luh SP, Chou MC, Wang LS, et al. Video-assisted thoracoscopic surgery in the treatment of complicated parapneumonic effusions or empyemas: outcome of 234 patients. Chest. 2005;127:1427-32.

3. Solaini L, Prusciano F, Bagioni P. Video-assisted thoracic surgery in the treatment of pleural empyema. Surg Endosc. 2006;21:280-4.

4. Wozniak CJ, Paull DE, Moezzi JE, et al. Choice of first intervention is related to outcomes in the management of empyema. Ann Thorac Surg. 2009;87:1525-31.

5. Chambers A, Routledge T, Dunning J, et al. Is video-assisted thoracoscopic surgical decortication superior to open surgery in the management of adults with primary empyema? Interact Cardiovasc Thorac Surg. 2010;11:171-7.

6. Shahin Y, Duffy J, Beggs D, et al. Surgical management of primary empyema of the pleural cavity: outcome of 81 patients. Interact Cardiovasc Thorac Surg. 2010;10:565-7.

7. Chen JS, Huang KC, Chen YC, et al. Pediatric empyema: outcome analysis of thoracoscopic management. J Thorac Cardiovasc Surg. 2009;137:1195-9.

8. Light RW. A new classification of parapneumonic effusions and empyema. Chest. 1995;108:299-301.

9. Pugh RN, Murray-Lyon IM, Dawson JL, et al. Transection of the oesophagus for bleeding oesophageal varices. Br J Surg. 1973;60:646-9.

10. Chen YS, Lin JW, Yu HY, et al. Cardiopulmonary resuscitation with assisted extracorporeal life-support versus conventional cardiopulmonary resuscitation in adults with in-hospital cardiac arrest: an observational study and propensity analysis. Lancet. 2008;372:554-61.

11. Chen DS. From hepatitis to hepatoma: lessons from type B viral hepatitis. Science. 1993;262:369-70.

12. Chen YC, Chu CM, Yeh CT, et al. Natural course following the onset of cirrhosis in patients with chronic hepatitis B: a long-term follow-up study. Hepatol Int. 2007; 1:267-73.

13. Dai CY, Ho CK, Huang JF, et al. Hepatitis $C$ virus viremia and low platelet count: a study in a hepatitis B \& C endemic area in Taiwan. J Hepatol. 2010;52:160-6.

14. Lu SN, Su WW, Yang SS, et al. Secular trends and geographic variations of hepatitis $\mathrm{B}$ virus and hepatitis $\mathrm{C}$ virus-associated hepatocellular carcinoma in Taiwan. Int J Cancer. 2006;119:1946-52.

15. Fernandez-Esparrach G, Sanchez-Fueyo A, Gines P, et al. A prognostic model for predicting survival in cirrhosis with ascites. J Hepatol. 2001;34:46-52.

16. Friedman LS. Surgery in the patient with liver disease. Trans Am Clin Climatol Assoc. 2010;121:192-204.

17. Chen KY, Hsueh PR, Liaw YS, et al. A 10-year experience with bacteriology of acute thoracic empyema: emphasis on Klebsiella pneumoniae in patients with diabetes mellitus. Chest. 2000;117:1685-9.

18. Lin YT, Chen TL, Siu LK, et al. Clinical and microbiological characteristics of community-acquired thoracic empyema or complicated parapneumonic effusion caused by Klebsiella pneumoniae in Taiwan. Eur J Clin Microbiol Infect Dis. 2010;29:1003-10. 
19. Chen $\mathrm{CH}$, Shih CM, Chou JW, et al. Outcome predictors of cirrhotic patients with spontaneous bacterial empyema. Liver Int. 2011;31:417-24.

20. Heffner JE, Klein JS, Hampson C. Interventional management of pleural infections. Chest. 2009;136:1148-59.

21. Cassina PC, Hauser M, Hillejan L, et al. Video-assisted thoracoscopy in the treatment of pleural empyema: stage-based management and outcome. J Thorac Cardiovasc Surg. 1999;117:234-8.
22. Novitsky YW, Litwin DE, Callery MP. The net immunologic advantage of laparoscopic surgery. Surg Endosc. 2004;18:1411-9.

23. Ng CS, Whelan RL, Lacy AM, et al. Is minimal access surgery for cancer associated with immunologic benefits? World J Surg. 2005;29:975-81.

24. Chen KC, Chen JS, Kuo SW, et al. Descending necrotizing mediastinitis: a 10year surgical experience in a single institution. J Thorac Cardiovasc Surg. 2008; $136: 191-8$

Access to The Journal of Thoracic and Cardiovascular Surgery Online is reserved for print subscribers!

Full-text access to The Journal of Thoracic and Cardiovascular Surgery Online is available for all print subscribers. To activate your individual online subscription, please visit The Journal of Thoracic and Cardiovascular Surgery Online, point your browser to http://www.mosby.com/itcvs, follow the prompts to activate your online access, and follow the instructions. To activate your account, you will need your subscriber account number, which you can find on your mailing label (note: the number of digits in your subscriber account number varies from 6 to 10). See the example below in which the subscriber account number has been circled:

\section{Sample mailing label}

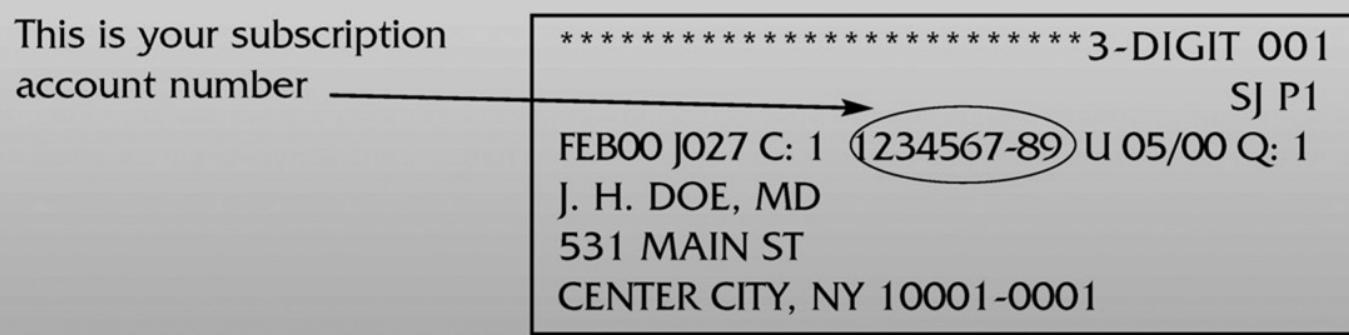

Personal subscriptions to The Journal of Thoracic and Cardiovascular Surgery Online are for individual use only and may not be transferred. Use of The Journal of Thoracic and Cardiovascular Surgery Online is subject to agreement to the terms and conditions as indicated online. 